\title{
AN INCREASED FREQUENCY OF CARPAL TUNNEL SYNDROME IN SARCOIDOSIS
}

\author{
Results of a study based on nerve conduction study \\ Halil Yanarda $\breve{g}^{1}$, Ömer Nuri Pamuk ${ }^{2}$, Meral Kızıltan ${ }^{3}$, Hilal Yıldiz $^{3}$, Sabriye Demirey ${ }^{1}$, Tuncer Karayel ${ }^{1}$
}

University of İstanbul, Cerrahpaşa Medical Faculty: Department of Lung Diseases ${ }^{1}$, Department of Neurology; University of Trakya, Trakya Medical Faculty: Department of Rheumatology ${ }^{2}$

Summary: Sarcoidosis is a systemic disease which affects the musculoskeletal system; however, its association with carpal tunnel syndrome (CTS) has been reported only rarely. In our study, we tried to determine the prevalence of CTS in our consecutive sarcoidosis patients based on their symptoms and nerve conduction study (NCS). Fiftysix patients (mean age: 45.2) who were followed up with the diagnosis of sarcoidosis at our center and who gave informed consent for NCS were included into the study. The patients were questionned for the presence of hand symptoms: paresthesia, pain, nocturnal paresthesia and/or pain, and, they underwent NCS. Ten (17.9\%) patients had recurrent paresthesia, 12 (21.4 \%) had pain, and $8(14.3 \%)$ had nocturnal paresthesia and/or pain. The results of NCS showed that $41 \%$ of the patients had findings compatible with CTS. Extrapulmonary involvement was significantly more frequent in these patients when compared to patients without CTS $(p=0.04)$. Also, patients with CTS were older than the others and CTS-associated symptoms were more frequent in them although this was not significant $(p>0.05)$. In this study, by performing NCS we detected quite a high prevalence of CTS in our sarcoidosis patients. The fact that most of the patients were asymptomatic was interesting.

Key words: Sarcoidosis; Carpal tunnel syndrome; Nerve conduction study; Paresthesia; Pain

\section{Introductions}

Sarcoidosis is a multisystem disease of unknown etiology. The frequency of neurologic manifestations in sarcoidosis varies between $5 \%$ to $15 \%$ (7). Carpal tunnel syndrome (CTS) is the most frequently encountered entrapment neuropathy and occurs as a result of the compression of the median nerve as it passes through the carpal tunnel. CTS might be seen during the course of many systemic diseases, metabolic disorders, inflammatory arthrites, etc. (17). Although CTS during the course of various infiltrative diseases is well-known, its presence in sarcoidosis has been reported in only one series (13). In this study, we aimed to find out the frequency of CTS in sarcoidosis patients followed up at our department while evaluating the clinical features of subjects with CTS.

\section{Materials and methods}

This study was conducted between 1998-2001 at Cerrahpaşa Medical Faculty. Sixtytwo consecutive sarcoidosis patients were asked whether they had recurrent symptoms of pain and paresthesias involving two of the first four hand digits, and also whether they were awakened from sleep by pain and/or parestesia. Later, all these patients were asked to undergo nerve conduction studies (NCS). Fiftysix of those (mean age: $45.2 \pm 12.1$ ) who gave informed consent for NCS were included into the study. The patients' age, sex, disease duration, the presence of extrapulmonary involvement, stage according to chest X-ray, biopsy results and previous medical therapies were obtained from the medical charts. Also, results of the most recent pulmonary function tests were recorded down. For pulmonary function tests, reference values according to the Eurepean Community for coal and steel were used (14).

Patients were diagnosed as sarcoidosis based on clinical, radiological and histopathological data. Histopathological diagnosis was reached by transbronchial biopsy obtained by fiberoptic bronchoscopy in 36 cases, mediastinoscopic biopsy in 14 cases, skin biopsy in 5 cases, peripheral lymph node biopsy in one case. Chest X-rays were classified according to De Remee (2) with stage I being bilateral hilar lymphadenopathy (BHL), stage II BHL plus parenchymal infiltration, and stage III parenchymal infiltration without BHL. 
Sarcoidosis patients who had diseases like diabetes mellitus, hypothyroidism, amyloidosis, rheumatologic diseases, history of fracture of the arm, superimposed peripheral neuropathy, ulnar neuropathy and cervical radiculopathy, and those who did not give permission for electrophysiologic studies were excluded from the study. Patients included into study underwent electrodiagnostic study - whether they had symptoms of CTS or not - after giving written consent.

The NCS were performed with the same device (Nihon Kohden Neuropack 2) under standard conditions, and the results were evaluated by the same neurologist. Standard median and ulnar motor and midpalmar-to-wrist NCS were performed (16). The median nerve motor NCS was considered abnormal when the distal latency exceeded $4.6 \mathrm{~ms}$ or the thenar compound muscle action potential (CMAP) amplitude was less than $4.0 \mathrm{mV}$. The median mixed palmar nerve action potential was regarded abnormal if the distal latency was greater than $2.2 \mathrm{~ms}$ or the median-ulnar palmar latency difference exceeded $0.4 \mathrm{~ms}$, when a distance of 8 $\mathrm{cm}$ was used between stimulation and recording sites. The median palmar amplitude was considered reduced if it was smaller than $50 \mu \mathrm{V}$. The minimal criteria for diagnosis of CTS were taken as prolongation of the median palmar absolute latency and an abnormal median-ulnar latency difference of greater than $0.4 \mathrm{~ms}$ or a median-ulnar palmar difference exceeding $0.4 \mathrm{~ms}$ if the median-palmar latency was less than $2.3 \mathrm{~ms}$. For the ulnar motor distal latency the upper limit of normal was $3.5 \mathrm{~ms}$ and for the hypothenar CMAP amplitude the lower limit was $6 \mathrm{mV}$. When a distance of $8 \mathrm{~cm}$ was used normal upper-palmar values were $2.2 \mathrm{~ms}$ and $15 \mu \mathrm{V}$. Hand temperature was monitored during study and kept at $31.5^{\circ} \mathrm{C}$ or higher. If the hands were below this temperature, they were warmed in a hot water bath. Needle-electrode examination was performed in all cases and included, the first dorsal interosseous, abductor pollicis brevis, flexor pollicis longus, pronator teres.

The age, sex, radiologic stage, extrapulmonary involvement, usage of steroids and disease duration were compared between subjects who had and did not have CTS according to EPS. For statistical analysis, chi-square and Mann-Whitney U tests were used.

\section{Results}

Of 56 sarcoidosis patients included into the study, 45 $(80.3 \%)$ were females and $11(19.7 \%)$ were males. Demographic data concerning the 56 consecutive sarcoidosis patients are presented in Table I. Radiologically, one patient had stage 0, 29 patients stage I, 21 patients stage II, and 5 patients had stage III disease. Extrapulmonary involvement was present in 40 patients. These were erythema nodosum (17 cases), skin involvement (15 cases), uveitis (11 cases), liver involvement (10 cases), arthritis ( 5 cases), spleen involvement (4 cases), peripheral lymph node involvement ( 4 cases), parotid gland and kidney involvement (one case each). The involvement of skin, parotid gland, lymph nodes, kidney and liver was confirmed by biopsy.

When their symptoms were asked before the NCS, 10 (17.9\%) patients defined recurrent paresthesia of the hands, $12(21.4 \%)$ patients defined pain of the hands, and $8(14.3 \%)$ patients admitted being awakened from sleep by paresthesia or pain. Six (10.7\%) patients had all of the three symptoms. Of 56 patients whose NCS were available, $41 \%$ (20 females, 3 males) had findings compatible with CTS. Three of 23 patients with CTS had only sensory median nerve lesion (pure sensory CTS), and 2 had pure median motor fibers lesion (motor CTS). Other patients had mixed CTS. None of the patients had pure axonal neuropathy.

When the clinical features of patients with and without CTS on NCS were compared, it was seen that patients with CTS had a higher frequency of symptoms associated with

Tab. 1: The distribution of the general features of the patients according to sex.

\begin{tabular}{|l|c|c|}
\hline & Female & Male \\
\hline $\mathrm{n}$ & 45 & 11 \\
\hline Mean age ( \pm SD) & $46.3 \pm 12.2$ & $40.4 \pm 10.9$ \\
\hline $\begin{array}{l}\text { Disease duration (months) } \\
\text { (mean } \pm \text { SD) }\end{array}$ & $21.7 \pm 22$ & $22.3 \pm 14.5$ \\
\hline $\begin{array}{l}\text { Extrapulmonary involvement, } \\
\mathrm{n}(\%)\end{array}$ & $33(73.3)$ & $7(63.6)$ \\
\hline Paresthesia, n (\%) & $8(17.8)$ & $2(18.2)$ \\
\hline Pain, n (\%)10 (22.2) & $2(18.2)$ & $1(9.1)$ \\
\hline $\begin{array}{l}\text { Awakened from sleep by } \\
\text { pain/paresthesia, n (\%) }\end{array}$ & $7(15.6)$ & 1 . \\
\hline
\end{tabular}

Tab. 2: The comparison of the general clinical features between sarcoidosis patients with and without CTS.

\begin{tabular}{|l|c|c|c|}
\hline Clinical features & CTS & No CTS & p \\
\hline $\mathrm{n}$ & 23 & 33 & - \\
\hline Female, n (\%) & $20(87)$ & $25(75.7)$ & $\mathrm{NS}$ \\
\hline Male, n (\%) & $3(13)$ & $8(24.3)$ & $\mathrm{NS}$ \\
\hline Paresthesia, n (\%) & $7(30.4)$ & $3(9.1)$ & 0.07 \\
\hline Pain, n (\%) & $7(30.4)$ & $5(15.2)$ & $\mathrm{NS}$ \\
\hline $\begin{array}{l}\text { Awakened from sleep } \\
\text { by pain/paresthesia, n (\%) }\end{array}$ & $5(21.7)$ & $3(9.1)$ & $\mathrm{NS}$ \\
\hline Mean age \pm SD & $48.3 \pm 11.4$ & $42.9 \pm 12.3$ & 0.09 \\
\hline Stage 0, I, n (\%) & $11(47.8)$ & $19(57.6)$ & $\mathrm{NS}$ \\
\hline Stage II, III, n (\%) & $12(52.2)$ & $14(42.4)$ & $\mathrm{NS}$ \\
\hline $\begin{array}{l}\text { Extrapulmonary involvement, } \\
\text { n (\%) }\end{array}$ & $20(87)$ & $20(60.6)$ & 0.04 \\
\hline Wrist arthritis, n (\%) & $3(13)$ & $2(6.1)$ & $\mathrm{NS}$ \\
\hline Steroid usage, n (\%) & $15(65.2)$ & $18(54.5)$ & $\mathrm{NS}$ \\
\hline Impaired PFT, n (\%) & $13(56.5)$ & $13(39.4)$ & $\mathrm{NS}$ \\
\hline $\begin{array}{l}\text { Mean disease duration } \\
\text { (months } \pm \text { SD) }\end{array}$ & $22.1 \pm 21.7$ & $21.6 \pm 20.1$ & $\mathrm{NS}$ \\
\hline
\end{tabular}

PFT: pulmonary function tests.

NS: not significant 
CTS and also had higher mean ages; however, these differences did not reach statistical significance $(p>0.05)$. The presence of CTS was confirmed in 3 of the 6 patients who had all 3 symptoms of CTS. In addition, extrapulmonary involvement was more frequent in patients with CTS $(p=0.04)$. The clinical features of sarcoidosis patients who had and did not have CTS are seen in Table 2.

\section{Discussion}

CTS might complicate different connective tissue diseases and is the most common entrapment neuropathy (9). Although various extrapulmonary complications of sarcoidosis have been defined, CTS has been reported in only a few cases. In this study, we aimed to detect the frequency of CTS in our sarcoidosis patients; $17.9 \%$ had recurrent paresthesia of the hands, $21.4 \%$ had pain of the hands, and $14.3 \%$ of the subjects awakened from sleep by paresthesia or pain. However, NCS revealed CTS in $41 \%$ of the patients. In a recent study, symptoms and/or signs of CTS were declared to be present in $44 \%$ of the sarcoidosis patients (13). Also, findings associated with CTS were detected in $16 \%$ of the patients. However, the presence of CTS was confirmed by NCS in only a small proportion of the patients.

In one survey, the prevalence of symptoms related to CTS was said to be $14.4 \%$ in the general population (1). The same study found a prevalence of electrophysiologically-confirmed, symptomatic CTS in about $3 \%$ of women and $2 \%$ of men. Another study from Italy reported a mean annual crude incidence of CTS in 329 cases per 100000 person-years (11). Although we did not include a control group in our study, the frequency of CTS was highly increased when compared to the general population.

In our study, we performed NCS to evaluate the frequency of CTS. As a result, we detected quite a high frequency of CTS in our sarcoidosis patients who were clinically asymptomatic. The most sensitive method used for the diagnosis of CTS is NCS (9). It is said that Tinnel and Phalen signs have limited sensitivity and specificity $(5,8)$. In studies comparing NCS and signs on physical examination, it was concluded that NCS were much more sensitive (12). However, it was documented that NCS might yield false positive and negative results $(3,6)$. In the study by Ferri et al. (3) which was performed in a community setting, only a little correlation between the patterns of hand symptoms and abnormal NCS was found. This study detected abnormal NCS in $60 \%$ of the subjects who did not have any hand symptoms.

In this study, we observed that patients with CTS were nonsignificantly older than the others (Table 2). Also, most patients with CTS were females. However, as the number of male sarcoidosis patients in our study was low; we were unable to make reliable statistical analysis. Studies about CTS conducted in the general population report that the frequency of CTS increases with age, and that the symptoms are seen in females more frequently (1).
It is hypothesized that wrist synovitis and granuloma deposition on the transverse carpal ligament -similar to the case in amyloidosis- might play a role in the development of CTS in sarcoidosis patients (13). In one sarcoidosis patient with CTS, noncaseified granulomas were demonstrated on the flexor retinaculum (10). Also, rarely the presence of noncaseified granulomas were shown on the nerve itself (15). In our study, biopsy was performed in none of the cases. Wrist synovitis was a little more frequent in our patients with CTS, the difference was not significant. Niemar et al. (13) reported a decreased incidence of Tinnel sign in their patients using steroids - probably, due to suppression of the inflammation of the median nerve; however, the incidence of steroid usage was not significantly different between our patients with and without CTS.

Peripheral neuropathy is one of the main types of neurologic involvement seen during the course of sarcoidosis (7). In one study, it was reported in $33 \%$ of the cases (4). Peripheral neuropathy during the course of sarcoidosis is a late sign and implies a disease with a chronic course $(4,7)$. We excluded patients with known peripheral neuropathy at the beginning of our study; and we did not diagnose sarcoidosis-related neuropathy in any of our patients. The disease duration in our patients with CTS was no different than the others. However, the frequency of extrapulmonary involvement was higher in subjects with CTS. Our results suggest that rather than disease duration, disease with extrapulmonary findings increases the risk of CTS.

The NCS findings suggest that CTS is common in sarcoidosis, and electrophysiologic examination is the method of diagnosis in the early, asymptomatic period of CTS. Further studies need to be conducted to enlight the etiopathogenesis of CTS in sarcoidosis. In addition, asymptomatic patients with positive findings on NCS need to be followed up for the development of symptomatic CTS.

\section{References}

1. Atroshi I, Gummesson C, Johnson R, Ornstein E, Ranstam J, Rosen I. Prevalence of carpal tunnel syndrome in a general population. JAMA 1999; 282:153-8.

2. De Remee RA. The roentgenographic staging of sarcoidosis. Historic and contemporary perspective. Chest 1983;1:128-33.

3. Ferry S, Silman AJ, Pritchard T, Keenan J, Croft P. The association between different patterns of hand symptoms and objective evidence of median nerve compression: a community based survey. Arthritis Rheum 1998;41:720-4.

4. Ferriby D, de Seze J, Stojkovic T et al. Clinical manifestations and therapeutic approach in neurosarcoidosis. Rev Neurol 2000;156:965-75.

5. Golding DN, Rose DM, Selvarajah K. Clinical tests for carpal tunnel syndrome: an evaluation. Br J Rheumatol 1986;25:388-90.

6. Hamanaka I, Okutsu I, Shimizu K, Takatori Y, Ninomiya S. Evaluation of carpal tunnel pressure in carpal tunnel syndrome. J Hand Surg (Am) 1995;20:848-54.

7. Jarnier D, Series C. Neurosarcoidosis. Review of the literature. Neurochirurgie 1999;45:214-8.

8. Katz JN, Larson MG, Sabra A et al. The carpal tunnel syndrome: diagnostic utility of the history and physical examination findings. Ann Intern Med 1990;112:321-7.

9. Katz JN, Simmons BP. Carpal tunnel syndrome. N Engl J Med 2002;346: 1807-12.

10. Kersting-Sommerhoff B, Hof N, Golder W, Becker G, Werber KD. MRI of the wrist joint "Granulomatous tenovaginitis of the sarcoidosis type" a rare cause of carpal tunnel syndrome. Roentgenpraxis 1995;48:206-8.

11. Mondelli M, Giannini F, Giacchi M. Carpal tunnel syndrome incidence in a general population. Neurology 2002;58:289-94. 
12. Nakazumi Y, Hamasaki M. Electrophysiological studies and physical examinations in entrapment neuropathy: sensory and motor functions compensation for the central nervous system in cases with peripheral nerve damage. Electromyogr Clin Neurophysiol 2001;41:345-8.

13. Niemer GW, Bolster MB, Buxbaum L, Judson MA. Carpal tunnel syndrome in sarcoidosis. Sarcoidosis Vasc Diffuse Lung Dis 2001;18:296-300.

14. Quanier PH. Standardized lung function testing. Bull Eur Physiopathol Respir 1983;Suppl.5.

15. Said G, Lacroix C, Plante-Bordeneuve V, et al. Nerve granulomas and vasculiti in sarcoid peripheral neuropathy: a clinicopathological study of 11 patients. Brain 2002;125:264-75.

16. Stevens JC. AAEE minimonograph \#26:The electrodiagnosis of carpal tunnel syndrome. Muscle Nerve 1987;10:99-113.

17. Stevens JC, Beard CM, O'Fallon WM, Kurland LT. Conditions associated with carpal tunnel syndrome. Mayo Clin Proc 1992;67:541-8.

Submitted February 2003.

Accepted September 2003

Doç. Dr. Halil Yanardă̆, İstanbul Üniversitesi, Cerrahpaşa Tip Fakültesi, Iç Hastalıkları Ana Bilim Dalı, Akciğer Hastalıkları Bölümü, Aksaray, İstanbul, Turkey. e-mail: halilyanardag@yahoo.com 